\title{
Assessment of Pollution Risk Mapping Methods in an Eastern Mediterranean Catchment
}

\author{
Dimitrios Michalopoulos', Elias Dimitriou ${ }^{1,2^{*}}$ \\ 1 Hellenic Open University, School of Science and Technology, Patras, Greece, e-mail: dmich84@gmail.com \\ 2 Hellenic Centre for Marine Research, Institute of Inland Waters, Anavissos, Attika, Greece \\ * Corresponding author's e-mail: elias@hcmr.gr
}

\begin{abstract}
The protection and preservation of good groundwater quality is of critical importance worldwide, nowadays. Increasing urbanization, economic development and agricultural activities, combined with limited precipitation contribute to the quantitative and qualitative degradation of groundwater resources, especially in the eastern Mediterranean region. For this purpose, a series of actions are implemented including groundwater vulnerability mapping that can depict prone to pollution aquifers which need protection and/or restoration measures. In this study, the efficiency of two well-known methodologies (COP and DRASTIC) for groundwater vulnerability and pollution risk mapping was assessed in the Sperchios river basin. The vulnerability and pollution risk maps of the two methodologies were spatially compared to each other and the observed similarities and differences were discussed and explained. The output of the study shows that in the particular geoenvironmental conditions DRASTIC method performs better than the COP, particularly in the lowland, porous media aquifer.
\end{abstract}

Keywords: vulnerability mapping, pollution risk mapping, groundwater pollution, COP, DRASTIC

\section{INTRODUCTION}

Good quality freshwater resources are getting limited with an uneven geographical distribution during the last few decades, mainly due to pollution pressures from anthropogenic activities (Dimitriou 2008; Matiatos 2016). This problem is enhanced for the groundwater resources which degrade at an even faster pace due to the increasing pressure from climate change, population growth and economic activities (Eckhardt \& Stackelberg 1995; Zhang et al. 1996; Karatzas \& Psarropoulou 2014).

The assessment and mapping of groundwater vulnerability and pollution risk is a widely used, modern approach, to recognize and demarcate areas that are more prone to contamination than others, as a result of the physical protective mechanisms and the existing pollution pressures (Babiker et al. 2005; Dimitriou et al. 2008; Martínez-Bastida et. al 2010). The output from this process is important since it allows the prioritization of groundwater bodies based on their degree of groundwater vulnerability and pollution risk, which can then dictate the need for preventive and/or restoration measures.

The groundwater pollution risk depends on both the vulnerability of the aquifer (due to its natural characteristics) and the pollution loads above the soil surface (Dimitriou et al. 2008) and therefore an area can be characterized by high or very high vulnerability but at the same time of very low pollution risk, if the associated pollution pressures are limited. (Boughriba et al. 2010)

In order to assess the groundwater vulnerability several methods exist, each one having specific advantages and disadvantages. Gogu \& Dassargu (2000), and Gogu et al. (2003) applied various such techniques and performed a comparative assessment to identify the optimum methodology. The results of this study indicated that each method provided different results because the groundwater vulnerability is not a measurable quantity but a qualitative index, which often leads to ambiguous results. Nevertheless, in areas with spatially or temporally limited wa- 
ter and pollution related data, groundwater vulnerability and pollution risk mapping can offer valuable information for the sustainable management and protection of the groundwater resources (Dimitriou et al., 2008).

The recent legislative framework in most countries, including European Union member states (Groundwater Directive, 2006/118/EC) promotes the need to improve the groundwater management practices by using state-of-the-art techniques and approaches such as the vulnerability and pollution risk mapping.

In the particular study, two different vulnerability and risk assessment methods have been used (COP and DRASTIC) to compare and evaluate them in an Eastern Meditteranean case study area (Spercheios river - Central Greece). The COP method is a relatively newly developed approach within the European COST ACTION 620 project, (Zwahlen 2003) focusing mainly on the protection of carbonate aquifers (Daly et al. 2002; Vias et al.,2006; Karaouzas et al., 2008; Dimitriou et al. 2008; Polemio et al., 2009). The DRASTIC methodology (Aller et. al. 1987) is widely used approach which has provided satisfactory results mainly on porous media aquifers
(Babiker et al. 2005; Panagopoulos et al., 2006; Voudouris et al. 2010).

\section{METHODOLOGY}

\section{Study Area}

Sperchios' basin is located on the East of continental Greece (Fig. 1) and covers an area of 1818 $\mathrm{Km}^{2}$ with an average height of $636 \mathrm{~m}$ (Dimitriou et al. 2011). The topographic terrain is particularly steep towards the south with an average slope of 33\% (Psomiadis 2010), due to Mountain Oiti (maximum altitude $2150 \mathrm{~m}$ ). The basin is structured by igneous and sedimentary rocks with the greater percentage of the area covered by flysch formations (41\%) followed by alluvial deposits (24.9\%), carbonate rocks (19.4\%) and ophiolitic formation (10\%, Fig. 1).

The main land uses in the area are: a) agricultural (26.4\% of the basin), b) pastures (34.1\%), c) forests (34.8\%) and d) urban or abandoned areas 4.7\% (Dasenakis et al. 2007). The average monthly temperatures range within the year from $6.9^{\circ} \mathrm{C}$ to $26.1^{\circ} \mathrm{C}$, while the aver-

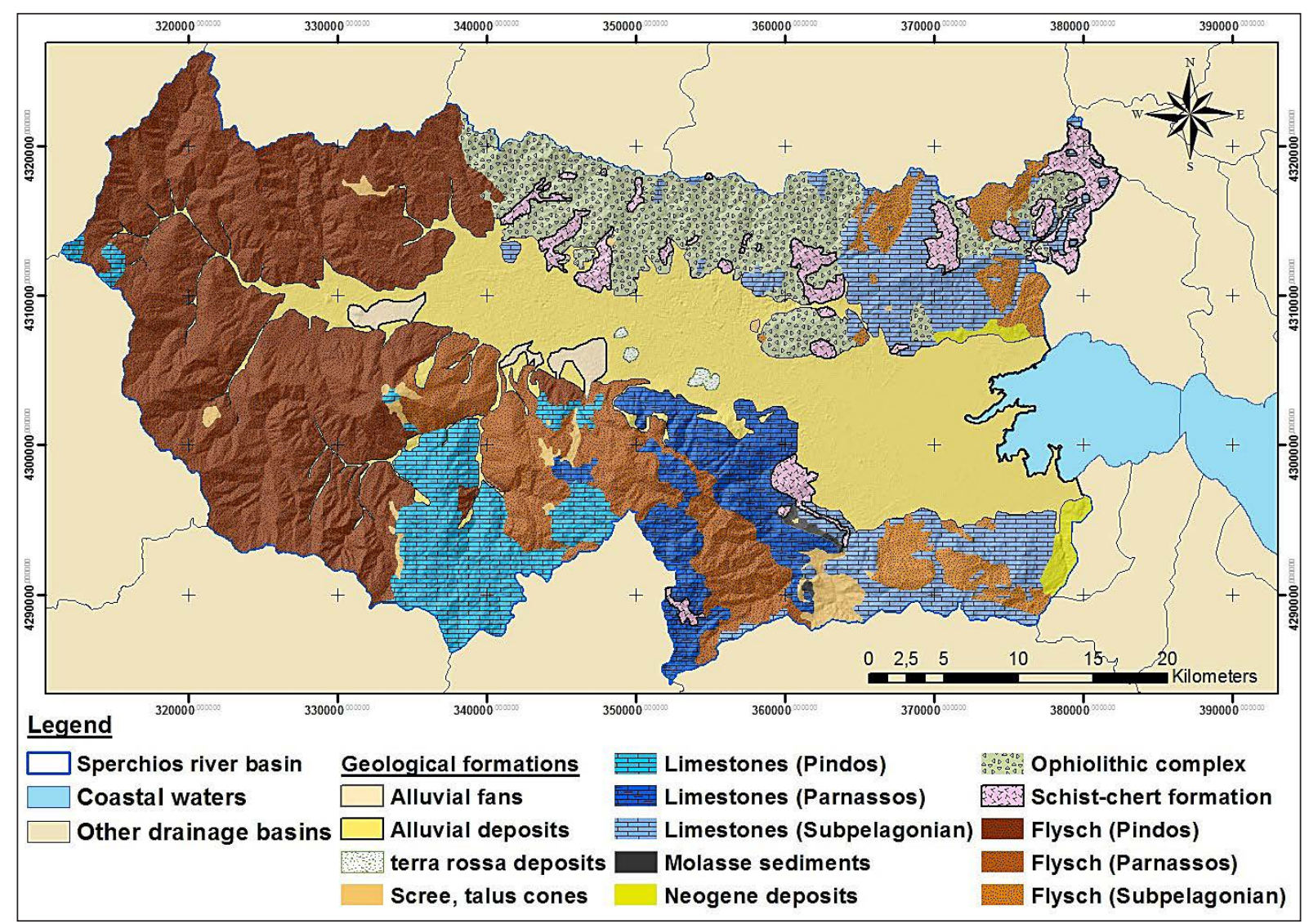

Figure 1. Geological map of Sperchios catchment 
age annual precipitation varies strongly within the basin from $515 \mathrm{~mm}$ to $1693 \mathrm{~mm}$ (due to orographic effect).

\section{COP Method}

The COP methodology (Zwahlen 2003) was developed under the European program COST ACTION 620 in order to assess and map the general vulnerability, especially in karstic aquifers. It is the acronym of the three main factors $\mathrm{C}, \mathrm{O}, \mathrm{P}$ used for the vulnerability assessment of the aquifer. It represents an important step forward in assessing the vulnerability of groundwater inside the karst aquifers, particularly in Mediterranean-type conditions (Vias et al. 2006). It takes into account the specific hydrogeological properties of karst formations and can be implemented, considering variable climatic conditions and different types of carbonate aquifers, in both diffuse flow and in pipe flow systems (Polemio et al. 2009). This method produces three maps for the study area that describe: (a) the flow concentration (C map), (b) the protection of the overlying layers of the aquifer $(\mathrm{O}$ map) and (c) the rainfall regime (P map) which can affect positively or negatively the natural protection (Dimitriou et al. 2008; Karaouzas et al. 2009).

For the construction of the aforementioned maps, geological, topographical, and soil maps have been acquired by the Institute of Geological and Mineralogical Explorations (IGME) and the Geographic Topography Department of the Hellenic Army while for the land use map, the Corine Land Cover system has been used. A series of recent hydrogeological studies provided additional data for the study area (Dasenakis et al. 2005; Psomiadis 2010).

To construct the C Map, the study area was classified according to the degree of karstification (the existence of permeable - impermeable surface layers) based on the geological map, the inclination (from the topographic map) and vegetation cover ratio (from Forestry and land use maps) in accordance with the weighting factors of the methodology.

For the O Map, which describes the protection provided to the aquifer from the surface soil layers (soil cover $\left[\mathrm{O}_{\mathrm{s}}\right]$ ) and the overlying geological formations $\left(\mathrm{O}_{\mathrm{L}}\right)$, the data that was inserted regards: (a) the soil texture of overlying layers (clayey to sandy texture with thickness ranging from $0.5 \mathrm{~m}$ to $1 \mathrm{~m}$ ) and (b) the lithology and the conditions of the unsaturated zone (in formations with high to low permeability with aquifers ranging from confined to unconfined).

Finally, the P Map depicts the spatial distribution of the amount and intensity of rainfall in the basin (Karaouzas et al. 2009) and reflects the impact of rainfall on the transfer of the pollutant in the groundwater. The relevant precipitation data were acquired from the local network of meteorological stations belonging to the National Meteorological Service (NMS) and the National Observatory of Athens (NOA).

The algebraic multiplication of the three aforementioned maps produced the basin's vulnerability index which was classified on 5 vulnerability classes as indicated by the COP methodology (Zwahlen 2003).

\section{DRASTIC Method}

The DRASTIC method (Aller et al. 1987) is one of the most widely used for the assessment of groundwater vulnerability with several key hydrogeological parameters forming its basis. The DRASTIC technique is flexible and the user can modify it by adding parameters or by changing weighting factors (Al-Adamat et al. 2003; Voudouris 2006; Kazakis \& Voudouris 2015).

The word DRASTIC is an acronym resulting from the initials of: Depth to groundwater, Recharge rate, Aquifer media, Soil media, Topography, Impact of vadose zone and hydraulic Conductivity of the aquifer.

The DRASTIC Index (DI) calculated from the following equation:

$$
\begin{aligned}
\mathrm{DI}= & \mathrm{DrDw}+\mathrm{RrRw}+\mathrm{ArAw}+\mathrm{SrSw}+ \\
& +\mathrm{TrTw}+\mathrm{IrIw}+\mathrm{CrCw}
\end{aligned}
$$

where: the $r$ index is the value and the $\mathrm{w}$ index the weight of each parameter (Nobre et al. 2007).

The Drastic index (DI) is derived from the evaluation of each parameter with a weighting factor ranging from 1 to 5 (w index) and the value of each hydrogeological parameter with values ranging from 1 to 10 ( $\mathrm{r}$ index) based on their impact on the aquifer's vulnerability.

The same information and data was used for both vulnerability methods (COP and DRASTIC), while for DRASTIC the 'Depth to the Aquifer' parameter was extracted from datasheets regarding 107 boreholes in the area. The recharge rate $(\mathrm{R})$ resulted from the amount of rainfall in the basin multiplied by the relevant infiltration coef- 
ficients for each hydrogeologic formation type (Psomiadis 2010). The factors referring to the aquifer media (A) and the impact of the vadose zone (I) resulted from the use of the geological maps in combination with the boreholes description. The parameter of the hydraulic conductivity factor (C) was extracted by using the local hydrolithologic maps based on the permeability of the region's formations. Finally, the parameters mentioned in the soil media (S) and Topography (terrain inclination) (T) were calculated based on the corresponding soil and topographic maps with the use relevant GIS tools (ArcMap software).

\section{Risk mapping}

Groundwater Pollution Risk is defined as the possibility of an aquifer's quality to be degraded through transfer of chemical or other substances from surface pollution sources (Nobre et al. 2007). The Risk map is the result of the combination of the vulnerability and the pollution pressures map (Hazard map, Karaouzas et al. 2009). The hazard map was produced by using the Corine Land cover map for the study area after assigning a hazard index to each separate land cover class according to the relevant Cost Action 620 project methodology (Zwhalen 2003).

The product of each vulnerability map (COP and DRASTIC) with the respective hazard map was estimated based on the equation:

$$
\mathrm{R}_{\mathrm{i}}=\rho / \mathrm{H}_{\mathrm{i}}
$$

where: $R_{i}$ is the Risk intensity index,

$H_{i}$ the Hazard index and $\rho$ the vulnerability index from the vulnerability maps.

The resulting Risk maps incorporated 5 classes (from very low to very high), according to Table 1.

\section{Comparative assessment}

The vulnerability and risk maps from the COP and DRASTIC methods were initially compared in the ArcMap software by estimating the per- centage coverage for each class in the study area as well as the geographical trends of the differences and similarities. The descriptive statistics of the different maps were estimated and compared to each other while a qualitative comparison followed by using pollutants concentration maps in the lowland part of the catchment which were correlated with the risk indices of COP and DRASTIC maps. For this purpose, a network of validation points was created randomly in the ArcMap software by using a cell size of 300 meters. From these cells, the geographic coordinates were extracted, as well as the risk values from the two COP and DRASTIC maps respectively. Next, the 20277 pairs of risk values were used in a statistical analysis software (SPSS) to perform a similarity analysis.

Moreover, data regarding concentrations of Nitrate $\left(\mathrm{NO}_{3}\right)$ and Phosphate $\left(\mathrm{PO}_{4}\right)$ ions have been used to assess the efficiency of the examined methods, from existing boreholes based on earlier research efforts (Psomiadis 2010). The $\mathrm{NO}_{3}$ and $\mathrm{PO}_{4}$ concentrations have been spatially interpolated in the central part of the basin where the boreholes exist by using Spline interpolation algorithm. The risk values of the all the cells of the interpolated surface ( $300 \mathrm{~m}$ size) from COP and DRASTIC maps were correlated with the $\mathrm{NO}_{3}$ and $\mathrm{PO}_{4}$ concentrations of the same points in order to identify which method is in agreement with the data and therefore performs better.

All of the above comparisons illustrated the strengths and weaknesses of each method in the specific type of Eastern Mediterranean basins as well as the potential improvements that the methods need.

\section{RESULTS}

\section{Hazard map}

The hazard map of the case study area (Figure 2), indicates that the main polluting pressures appear in the lowlands, at the central part of

Table 1. Classification based on the categories of Risk map

\begin{tabular}{|c|c|c|c|c|c|}
\hline$\rho$ & $\mathrm{Hi}$ & $1 / \mathrm{Hi}$ & $\rho^{*}(1 / \mathrm{Hi})$ & \multicolumn{2}{|c|}{ Risk class } \\
\hline 5 & $0-24$ & $>0.042$ & $>0.167$ & 1 & Very low \\
\hline 4 & $24-48$ & $0.042-0.021$ & $0.167-0.063$ & 2 & Low \\
\hline 3 & $48-72$ & $0.021-0.014$ & $0.063-0.028$ & $\mathbf{3}$ & Moderate \\
\hline 2 & $72-96$ & $0.014-0.014$ & $0.028-0.010$ & 4 & High \\
\hline 1 & $96-120$ & $<0.010$ & $<0.010$ & 5 & Very high \\
\hline
\end{tabular}






Figure 2. Hazard map of Spercheios’ basin

Spercheios basin, where intensive farming activities and rural towns and villages without wastewater treatment plants systems exist. The highest pressures occur in areas where industries, quarries and sanitary landfills are sited, as well as settlements that are not connected to sewage networks or dispose their effluents in septic tanks. The rest of the area that covers mainly the mountainous part of the basin and consist of natural vegetation areas, are classified as of low and very low pollution hazard. This map has been combined with the following groundwater vulnerability maps from COP and DRASTIC methods to estimate the corresponding pollution risk maps.

\section{Vulnerability and Risk mapping}

The vulnerability maps (COP and DRASTIC) show that the areas that are mostly prone to pollution, are the ones consisting mainly by carbonate formations (Figures 3 and 4). Both methods display areas ranging from very high to very low vulnerability, while the very low vulnerability areas cover most of the examined basin in both methods.

Moderate vulnerability areas are the ones mainly covered by high-permeability limestone, with relatively steep slopes, presence of impermeable soil horizon and relatively high intensity rainfall. These conditions provide some degree of physical protection to the naturally vulnerable limestones which are therefore classified as of moderate vulnerability. Moreover, areas with karstified limestone of high permeability, with complete lack or permeable soil horizon, moderate slopes and rainfall intensity are classified as of high and very high vulnerability (Figures 3 and 4).

The main difference between the two vulnerability maps can be observed in the central, lowland part of the basin, where the DRASTIC method displays moderate and high vulnerability values where COP illustrates low vulnerability values (Figures 3 and 4). The vulnerability classes in the mountainous part of the basin are very similar in both methods apart from some specific, limited regions in which COP map is classified as of moderate and DRASTIC as of high vulnerability.

Both methods agree on the same classes in the largest part of the basin (72.59\%) which covers mainly the highland part of the basin (Table 2).

Most of the differences in vulnerability classification are located mainly in areas dominated by tertiary sediments, as well as in mountainous karstic formation regions at the northeast part of 


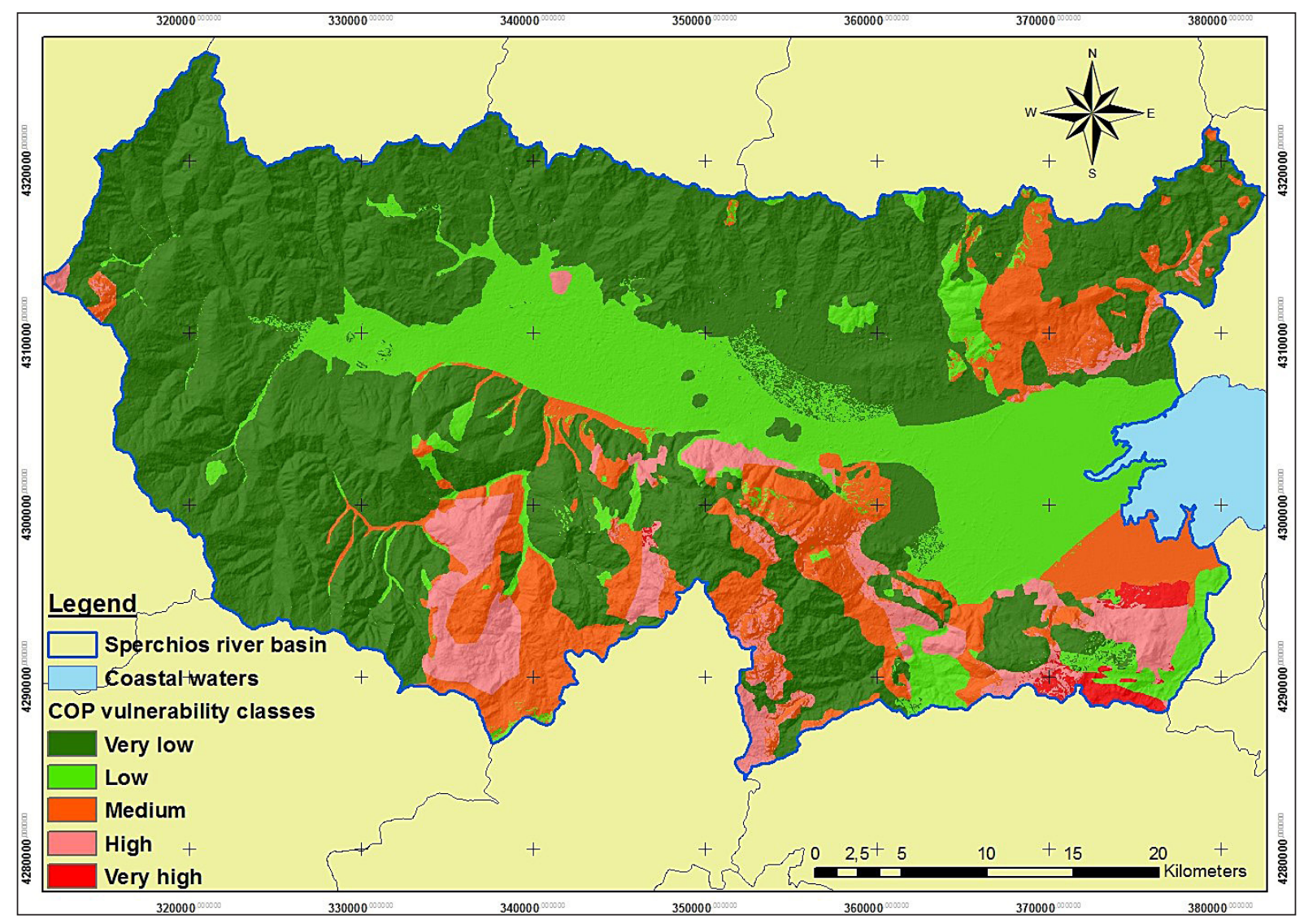

Figure 3. Vulnerability map of the COP method

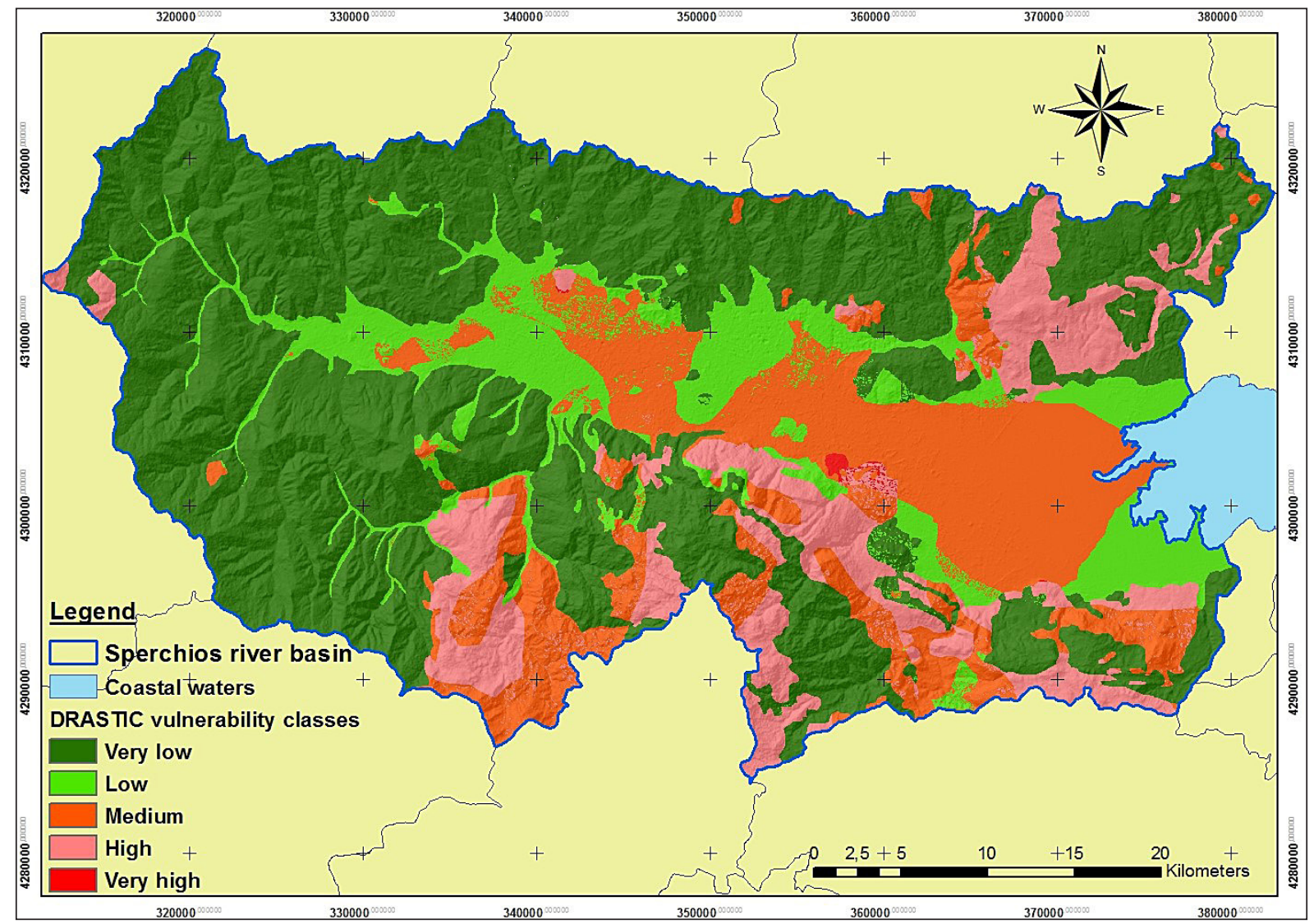

Figure 4. Vulnerability map of the DRASTIC method 
Table 2. Comparative table of DRASTIC - COP vulnerability classification

\begin{tabular}{|c|c|c|c|c|}
\hline Vulnerability classification & Area $\mathrm{km}^{2}$ & Area $\mathrm{km}^{2}$ (aggregate) & Area $\%$ & Area \% (aggretate) \\
\hline \multirow{3}{*}{ DRASTIC > COP } & 0.0088 & \multirow{3}{*}{411.18} & 0.0005 & \multirow{3}{*}{22.5} \\
\hline & 34.40 & & 1.88 & \\
\hline & 376.77 & & 20.63 & \\
\hline \multirow{2}{*}{ COP > DRASTIC } & 89.34 & \multirow{2}{*}{89.42} & 4.89 & \multirow{2}{*}{4.9} \\
\hline & 0.09 & & 0.005 & \\
\hline COP = DRASTIC & \multicolumn{2}{|c|}{1325.56} & \multicolumn{2}{|r|}{72.59} \\
\hline TOTAL & \multicolumn{2}{|c|}{1826.17} & \multicolumn{2}{|r|}{100} \\
\hline
\end{tabular}

the basin. In these areas, (22.5\% of the basin), the COP method indicates lower vulnerability than DRASTIC. Differences appear also in the southeast part of the basin (4.9\% of the basin) where, DRASTIC methodology displays lower vulnerability than COP (Table 2).

The commonly classified areas in both methods are geographically restricted to the mountainous part of the basin as well as to the southeastern part (figure 5). The central and eastern part of the basin (mainly alluvial sediments and ophiolites respectively) are classified differently (28\% of the basin). The degree of similarity between the two methods, in each vulnerability class, indicate that the highest agreement is in the very low vulnerability class (in $54.2 \%$ of the basin) while in the rest of the classes the agreement fluctuates from $0 \%$ (in very high vulnerability), to $7 \%$ in low vulnerability (Figure 6). COP map covers larger areas in the very low and low vulnerability classes while DRASTIC illustrates larger surfaces in moderate and high classes (more 'pessimistic' results).

Similarly, the risk maps of the two methods show values ranging from very low to high (4 classes), thus lacking values of very high risk (less than $1 \%$ of the basin in both methods, Figures 7 and 8, Table 3). This is because the hazard map of the study basin (Figure 2) il-

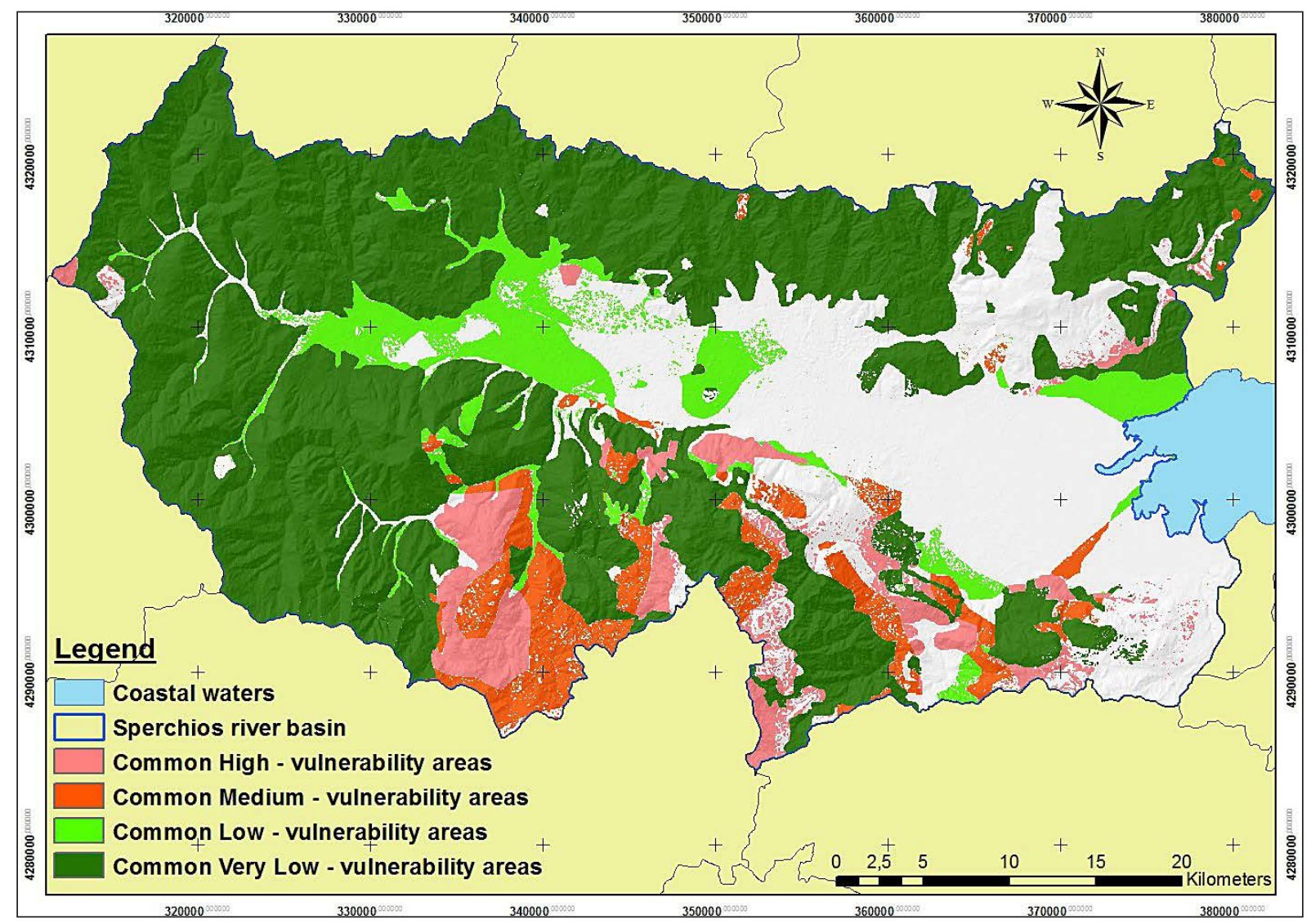

Figure 5. Common areas of the Drastic and COP methods for each vulnerability class 


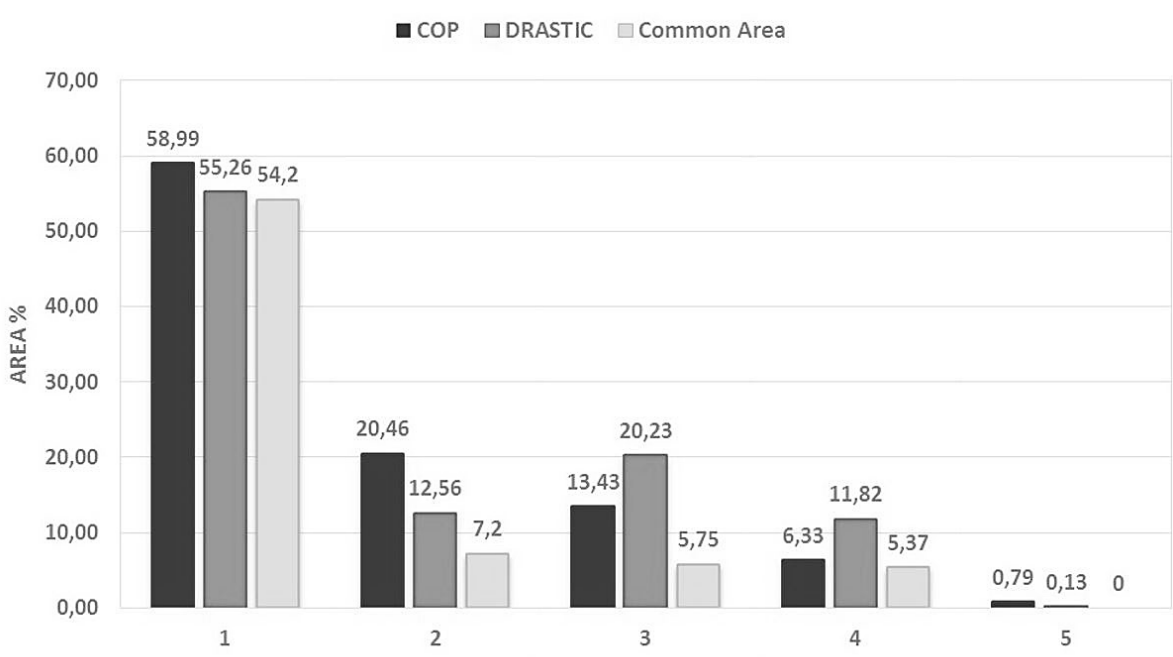

VULNERABILITYCLASSES

Figure 6. Comparative percentage bar chart of areas occupied by vulnerability classes

Table 3. Vulnerability and risk areas for each method

\begin{tabular}{|l|c|c|c|c|c|c|c|c|}
\hline \multirow{2}{*}{ Class } & \multicolumn{2}{|c|}{ Vulnerability COP } & \multicolumn{2}{c|}{ COP Risk } & \multicolumn{2}{c|}{ Vulnerability DRASTIC } & \multicolumn{2}{c|}{ DRASTIC Risk } \\
\cline { 2 - 10 } & Area $\mathrm{km}^{2}$ & Area $\%$ & Area $\mathrm{km}^{2}$ & Area $\%$ & Area $\mathrm{km}^{2}$ & Area $\%$ & Area $\mathrm{km}^{2}$ & Area $\%$ \\
\hline Very high & 14.46 & 0.79 & - & - & 2.41 & 0.13 & - & - \\
\hline High & 115.57 & 6.33 & 4.52 & 0.25 & 215.77 & 11.82 & 5.14 & 0.28 \\
\hline Medium & 245.22 & 13.43 & 49.25 & 2.70 & 369.49 & 20.23 & 192.69 & 10.56 \\
\hline Low & 373.68 & 20.46 & 429.85 & 23.51 & 229.37 & 12.56 & 286.38 & 15.68 \\
\hline Very low & 1077.26 & 58.99 & 1342.55 & 73.52 & 1009.16 & 55.26 & 1341.95 & 73.48 \\
\hline Total & 1826.17 & 100.00 & & & 1826.17 & 100.00 & & \\
\hline
\end{tabular}

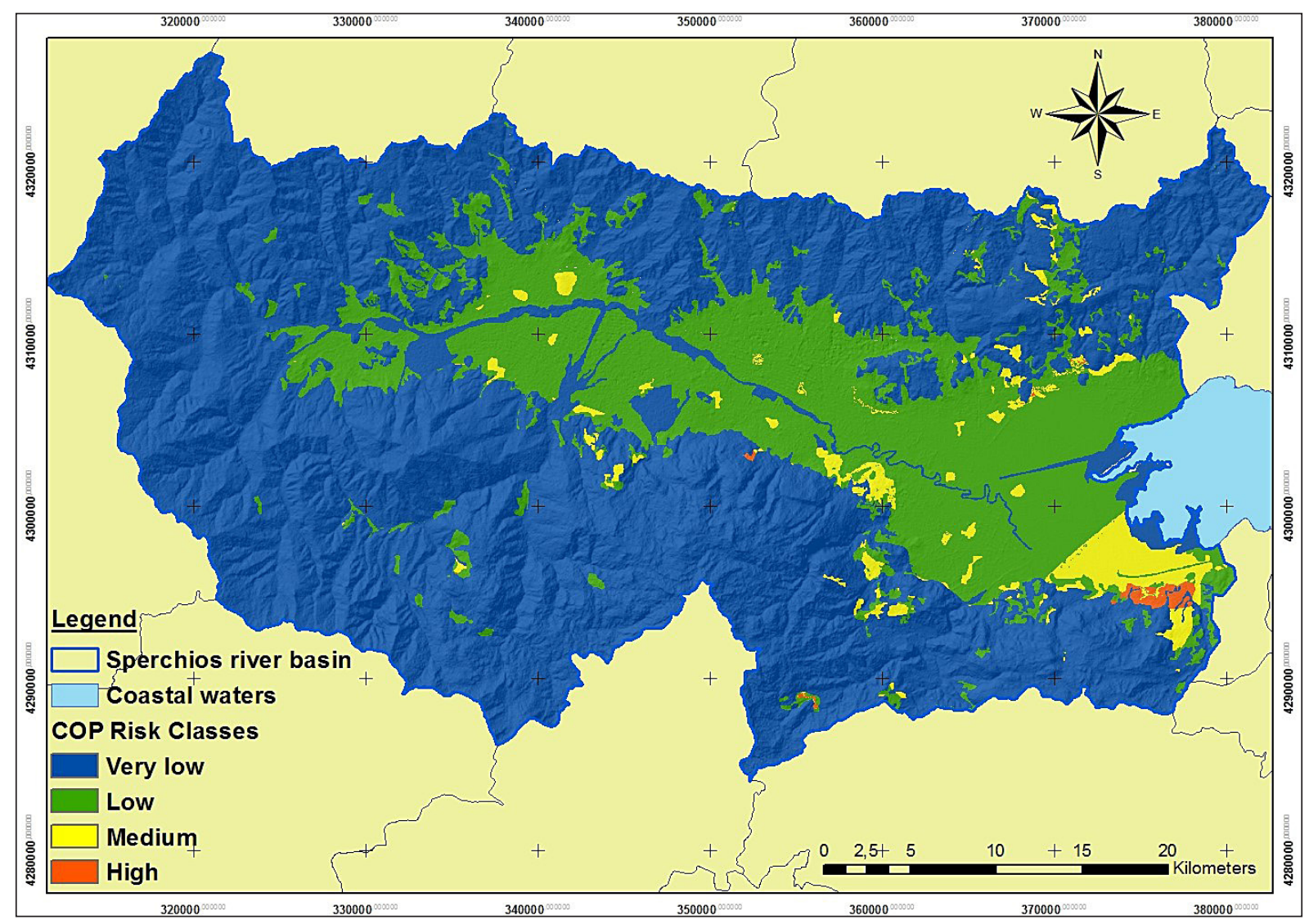

Figure 7. COP Risk map 


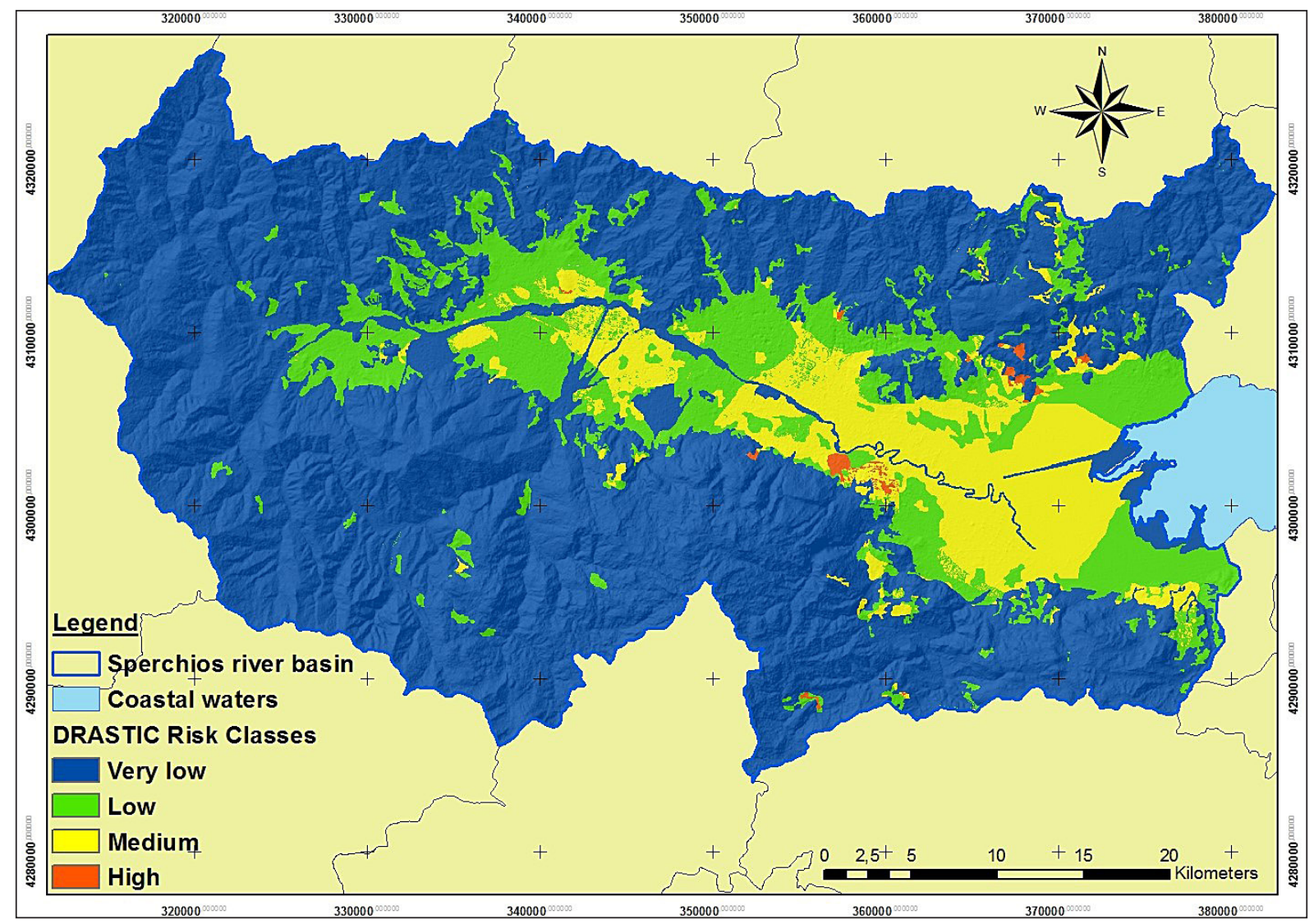

Figure 8. DRASTIC Risk map

lustrates very limited areas of high hazard and none of very high hazard. DRASTIC displays most of the lowland area as of moderate pollution risk while COP illustrates the same area as of low vulnerability. The peripheral, high altitude part of the basin is characterized as of very low pollution risk in both methodologies while DRASTIC presents a higher percentage of rural/urban areas as of moderate risk in relation to the COP.

\section{Statistical analysis of the Risk maps}

The validation points (20277 points) in the two risk maps (COP and DRASTIC) were strongly correlated, $(r=0.715)$ at $\mathrm{p}<0.05$, which indicate that both methodologies perform consistently, in a similar pattern, at the particular study area.

The distribution of the validation points in risk classes illustrates that for the very low risk category both methodologies perform almost identically (more than 99\% agreement) while in low risk class COP has 33\% more points than DRASTIC and in the moderate risk class DRASTIC incorporates approximately 3 times more points than COP (Fig. 9). This shows that DRAS-
TIC tends to be more "pessimistic", with respect to pollution risk, than COP. Moreover, the high pollution risk class points are below $0.3 \%$ of the total and the difference between the methods is negligible which do not allow for safe conclusions to be drawn for the particular class.

The descriptive statistics confirm the aforementioned statements since the mean and standard deviation of the risk index for Drastic is slightly higher than COP while kyrtosis and skewness are higher COP compared to DRASTIC (Table 4).

\section{Qualitative comparison of the two methods}

The methods efficiency was also assessed based on $\mathrm{NO}_{3}$ and $\mathrm{PO}_{4}$ concentrations from boreholes that exist mainly in the lowland part of the basin, on the alluvial aquifer. Thus, this comparison is mostly valid for the porous media aquifer where most of the pollution pressures and groundwater abstractions are located.

The distribution of $\mathrm{PO}_{4}$ in the study area shows high values (more than $1 \mathrm{mg} / \mathrm{l}$ ) in the eastern and western parts of the lowland area where relatively large towns and agricultural areas exist. 


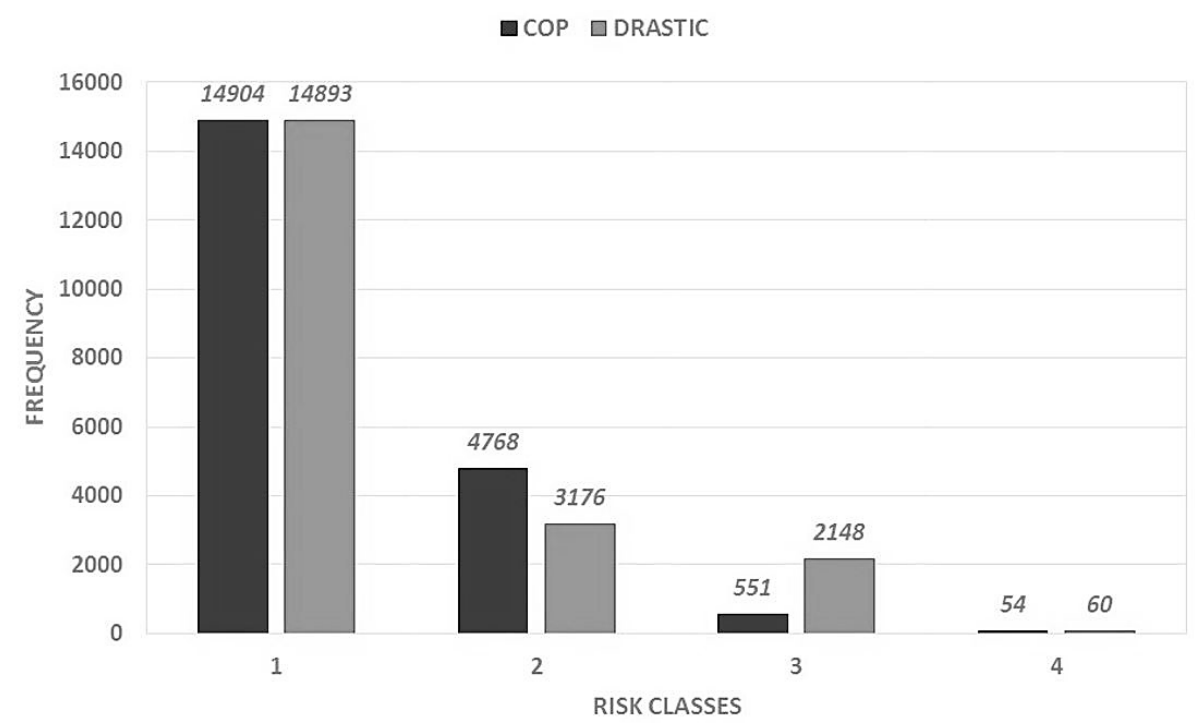

Figure 9. Frequency diagram of each method's risk class

Table 4. Analysis results of the two methods

\begin{tabular}{|l|l|l|c|}
\hline \multicolumn{2}{|c|}{ COP Risk } & \multicolumn{2}{c|}{ DRASTIC Risk } \\
\hline Mean & 1.297 & Mean & 1.377 \\
\hline Standard Error & 0.004 & Standard Error & 0.005 \\
\hline Standard Deviation & 0.529 & Standard Deviation & 0.682 \\
\hline Sample variance & 0.279 & Sample variance & 0.465 \\
\hline Kurtosis & 2.556 & Kurtosis & 1.230 \\
\hline Skewness & 1.686 & Skewness & 1.593 \\
\hline Sum & 26309 & Sum & 27929 \\
\hline Count & 20277 & Count & 20277 \\
\hline
\end{tabular}

The Spercheios deltaic region is also rich in $\mathrm{PO}_{4}$ which is expected due to the intensive farming practices that are applied there (Figure 10). The $\mathrm{NO}_{3}$ levels are particularly elevated (more than $60 \mathrm{mg} / \mathrm{l}$ ) in the northwest, central and southeast parts of the study area which coincide with extensive agricultural plains. The areas with high $\mathrm{NO}_{3}$ and $\mathrm{PO}_{4}$ concentrations (Figures 10 and 11) fall mostly within the moderate pollution risk zone in the DRASTIC map and within the low pollution risk zone in the COP map (Figures 7 and 8).

The frequency distribution diagrams of nitrate and phosphate ions are pretty similar for both methods in the very low pollution risk class (class 1) while the differences increase as pollution risk increases (Figures 12 and 13). The COP has a large part of its low pollution risk zone with $\mathrm{NO}_{3}$ values above $20 \mathrm{mg} / \mathrm{l}$, which is not the case for DRASTIC while the contrary is observed for the areas characterized as of moderate pollution risk (class 3, Figure 12). The COP method illustrates a significant part of the high risk zone in areas with relatively low $\mathrm{NO}_{3}$ values (below $20 \mathrm{mg} / \mathrm{l}$ ) while DRASTIC indicates a relatively smooth distribution of its high risk areas in $\mathrm{NO}_{3}$ values above $20 \mathrm{mg} / \mathrm{l}$ (with a peak at $60 \mathrm{mg} / 1$, figure 12). Regarding phosphates, both methods present similar patterns for the very low and low risk zones while in the moderate risk zone DRASTIC have a larger area distributed in high $\mathrm{PO}_{4}$ values than COP. However, in the high risk zone COP performs better than the DRASTIC method since it illustrates an increasing area as $\mathrm{PO}_{4}$ values increase (Figure 13). Therefore, given the above-mentioned trends, DRASTIC method is more efficient than COP in the lowland part of the basin, where alluvial aquifers exist which was partially expected since COP method focuses mostly on the protection of Karstic aquifers while DRASTIC structure is more compliant with the characteristics of sedimentary, free-surface groundwater bodies. 


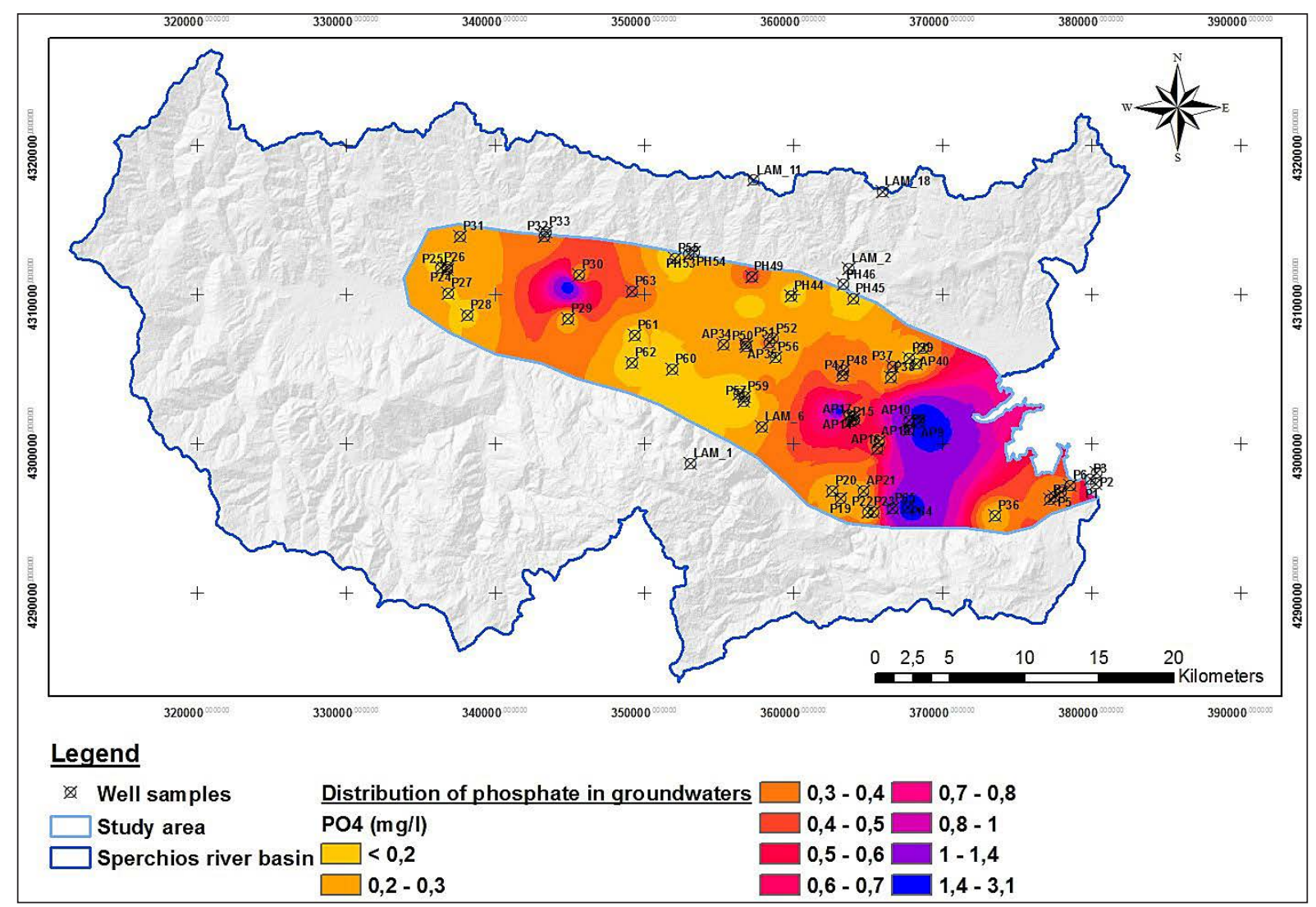

Figure 10. Phosphate allocation in central

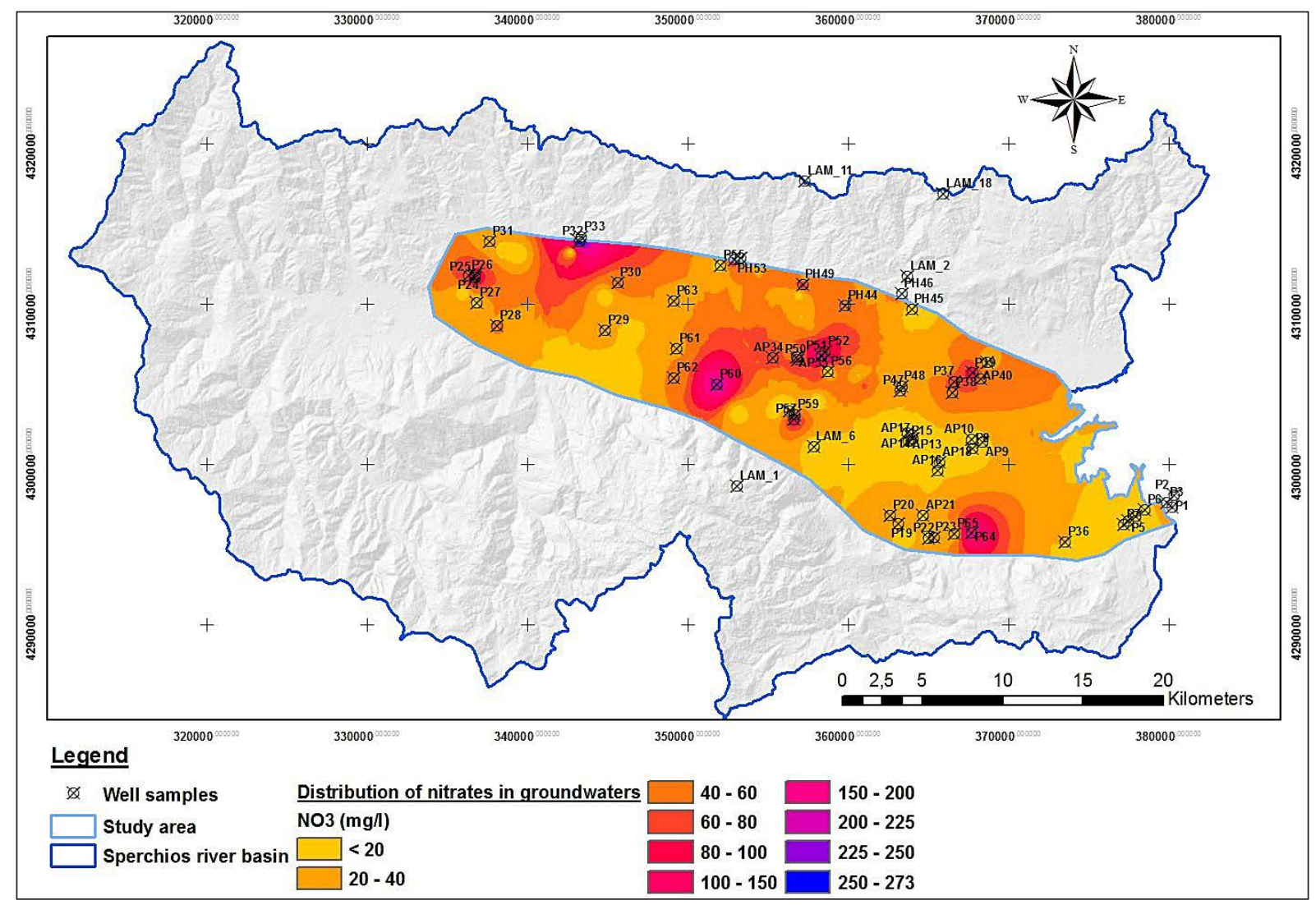

Figure 11. Nitrate allocation in central basin 

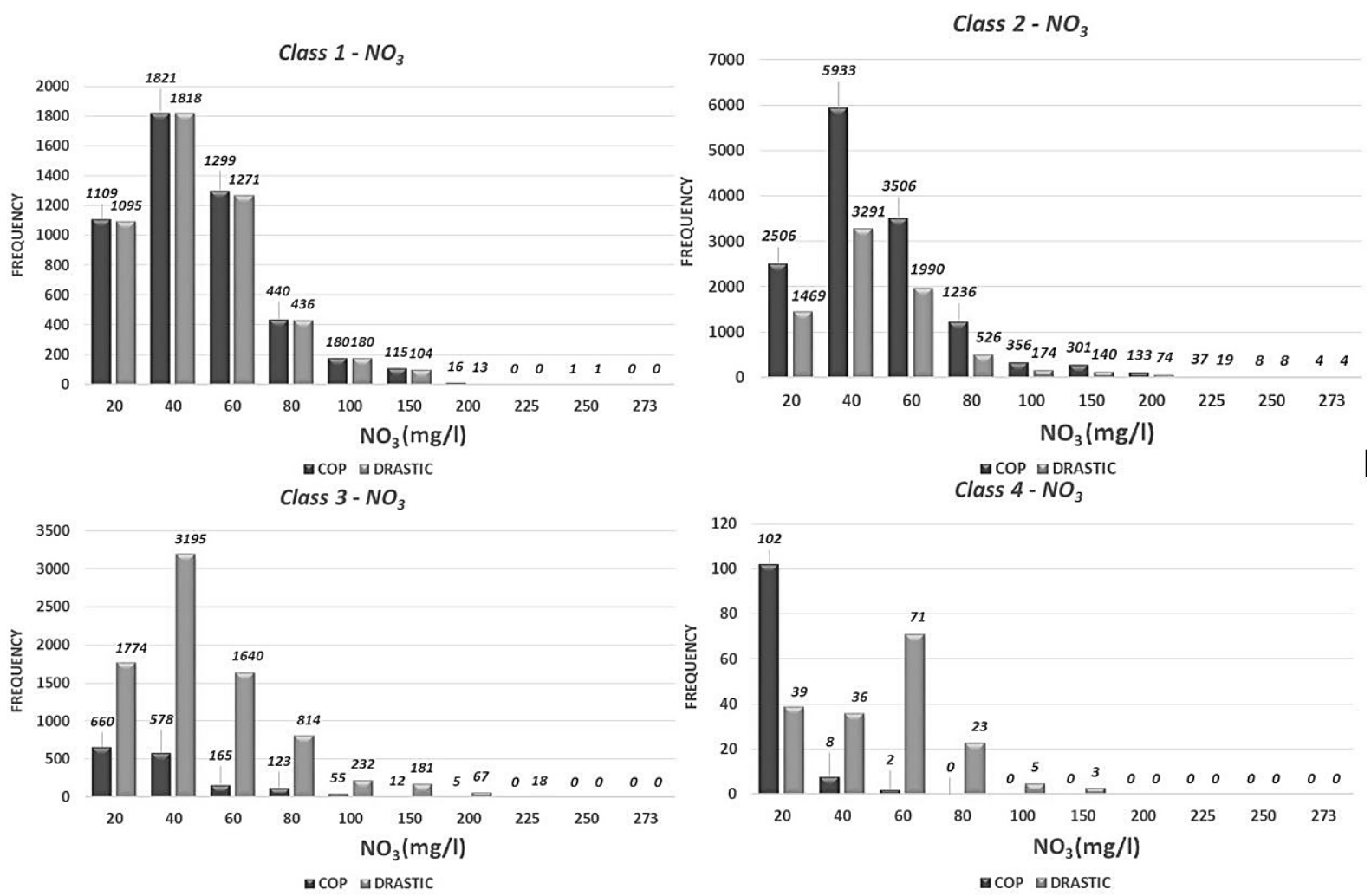

Figure 12. Frequency histograms of nitrates concentrations per risk class
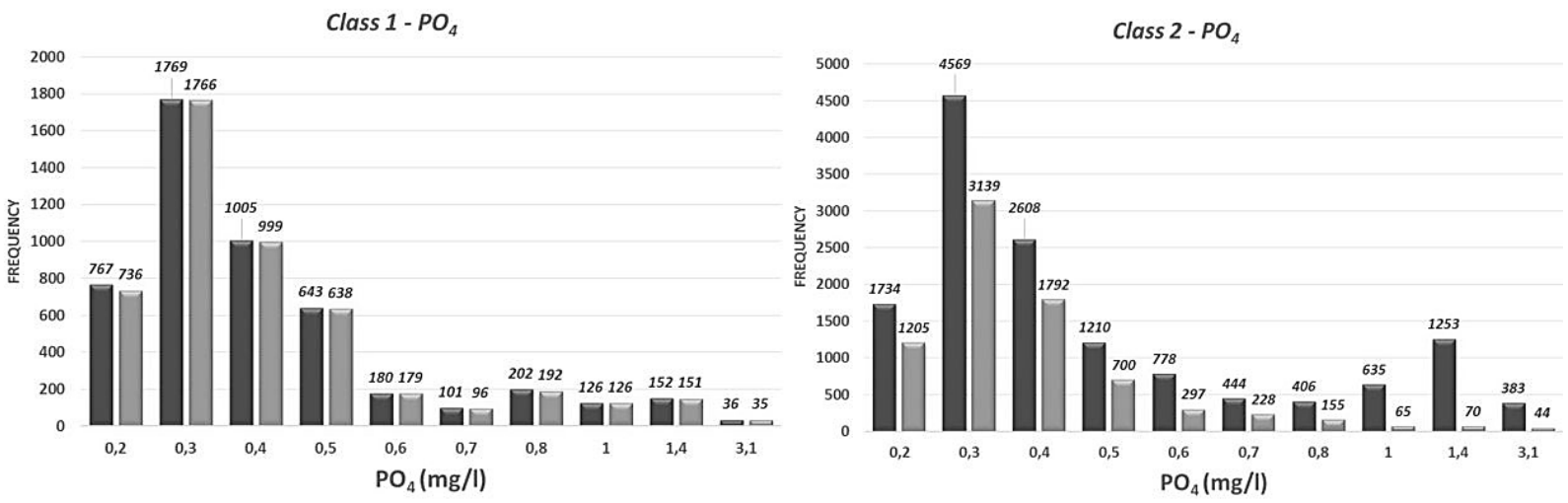

I COP $\triangle$ DRASTIC
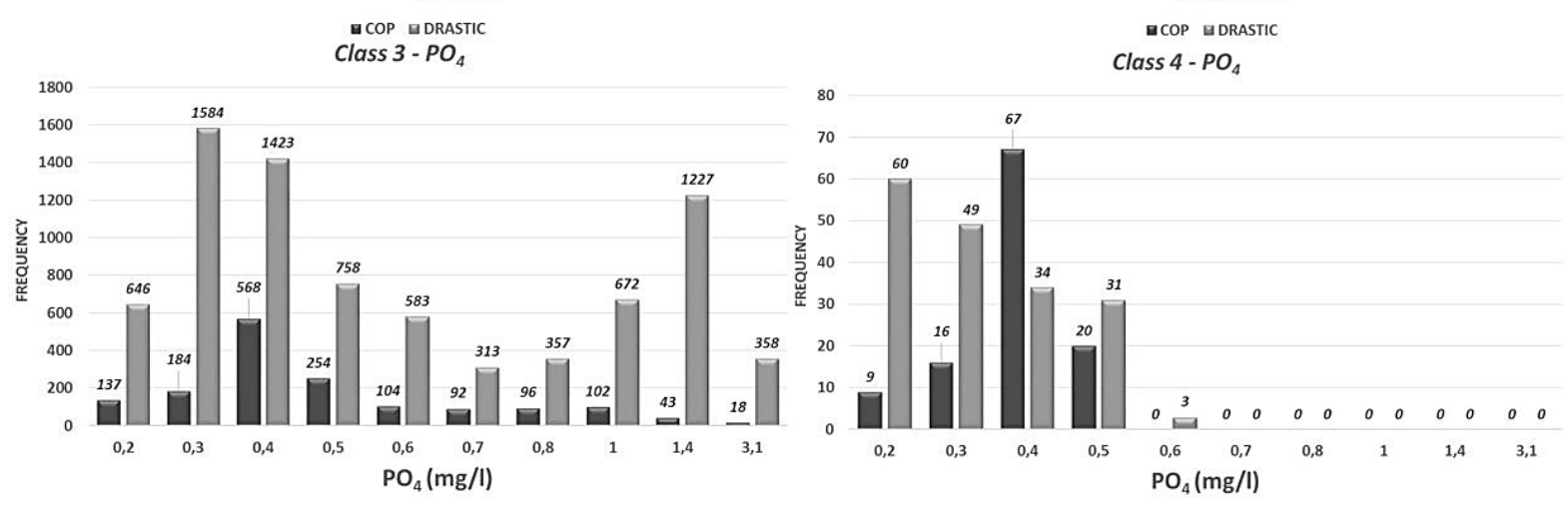

$\square$ COP $\square$ DRASTIC

G COP IDRASTIC

Figure 13. Frequency histograms of phosphate concentrations per risk class 


\section{CONCLUSIONS}

There are several research efforts attempting to compare vulnerability assessment methods under various geoenvironmental conditions (Sorichetta et al. 2013, Kazakis and Voudouris 2011, Pisciotta et al. 2015, Luoma et al. 2016) but very few include the relatively new COP method in the comparative assessment process.

Sorichetta et al. (2013), used multivariate Weights of Evidence (WofE) and Logistic Regression (LR) methods to identify the optimum solution for explaining nitrate pollution sources and the impacts on the groundwater in Milan, Italy. Kazakis and Voudouris (2011) compared DRASTIC, GOD and AVI methods in a Northern Greek basin and identified that GOD method produces similar vulnerability maps to the other two approaches. Moreover, Luoma et al. (2016) compared the AVI, modified SINTACS and GALDIT methods under climate scenarios in southern Finland and found out that the combined use of SINTACS and GALDIT methods could provide adequate information for vulnerability and seawater intrusion assessment.

In the particular study, an attempt to compare COP and DRASTIC methods has been made in an eastern Mediterranean basin that incorporates a variety of geological formations, intensive topographic relief and mainly agricultural land uses. The results indicated that both methods agree regarding their vulnerability classifications at over $70 \%$ of the basin while DRASTIC is a little bit more 'pessimistic' in the lowland part of the basin where alluvial deposits and porous media aquifers are encountered. The qualitative assessment of the corresponding risk maps with the nitrate and phosphate concentrations indicated that in the mountainous parts of the basin, both methods illustrate high similarity while in the agricultural plains there are significant differences. In these areas, DRASTIC method illustrates a slightly higher pollution risk (moderate) than COP (low) and the distribution of risk classes over the nutrients pollution map indicate that DRASTIC performs better in the lowland part of the basin.

A similar effort was conducted by Pisciotta et al. (2015) that used the IPNOA method (agricultural nitrates hazard index) combined with the SINTACS and DRASTIC vulnerability methods and identified that both methods present similar results with SINTACS being the most accurate approach.
Therefore, all vulnerability and pollution risk methods have specific advantages and shortcomings that can dictate the applicability of each one of them in a given case study. The COP method is more easy to apply since the parameters and input used are limited and relatively easy to find while DRASTIC needs more information which is not always available but provides better results in the porous media aquifers. Nevertheless, COP focuses on karstic formations which is often encountered in mountainous areas for which information regarding the depth of groundwater, recharge rates or hydraulic conductivity values are usually missing and therefore can provide a good alternative for assessing vulnerability and pollution risk in karstic mountainous aquifers.

\section{REFERENCES}

1. Aller L, Bennet T, Leher JH, Petty RJ, Hackett G. 1987, DRASTIC: a standardized system for evaluating ground water pollution potential using hydrogeological settings. US Enviromental Protection Agency, Report 600/2-85/018.

2. Al-Adamat, R.A.N., Foster, I.D.L., Baban, S.M.J. 2003, Groundwater vulnerability and risk mapping for the Basaltic aquifer of the Azraq basin of Jordan using GIS, Remote sensing and DRASTIC. Applied Geography (Sevenoaks, England), 23, 303-324.

3. Babiker I.S., Mohamed M., Hiyama T., Kato K. 2005, A GIS-based DRASTIC model for assessing aquifer vulnerability in Kakamigahara Heights, Gifu Prefecture, central Japan. Science of the Total Environment, 345, 127-140.

4. Boughriba M., Barkaoui A, Zarhloule Y., Lahmer Z., Houadi B., Verdoya M. 2010, Groundwater vulnerability and risk mapping of the Angad transboundary aquifer using DRASTIC index method in GIS environment, Arabian Journal of Geosciences, 3 (2), 207-220.

5. Daly D, Dassargues A, Drew D, Dunne S, Goldscheider N, Neale S, Popescu I.C, Zwahlen F. 2002, Main concepts of the "European approach" to karst-groundwater-vulnerability assessment and mapping, Hydrogeology Journal, 10, 340-345.

6. Dassenakis E., Kastritis A., Triantafyllaki S., Bourou P. and Paraskevopoulou V. 2005, Transport of pollutants in Sperchios catchment area and impacts to the coastal zone. Proceedings of the 5th Conference of the Hellenic Committee on Water Resources Management, Xanthi, Greece, pp. 210-211.

7. Dimitriou E., Karaouzas I., Sarantakos K., Zacha- 
rias I., Bogdanos I., Diapoulis A. 2008, Groundwater risk assessment at a heavily industrialised catchment and the associated impacts on a periurban wetland, Journal of Environmental Management, 88, 526-538.

8. Dimitriou E., Mentzafou A, Tzortziou M., Zeri Ch. 2011, Environmental monitoring and pollution pressures identification in Sperchios river catchment. Proceedings of the 3rd International CEMEPE \& SECOTOX Conference, Skiathos, pp. 323-328.

9. Eckhardt, D.A.V., Stackelberg, P.E. 1995. Relation of ground-water quality to land use on Long Island, New York Ground Water, 33, 1019-1033.

10. Gogu R.C., Dassargues A. 2000, Current trends and future challenges in groundwater vulnerability assessment using overlay and index methods, Environmental Geology 39 (6), 549-559.

11. Gogu R.C., Dassargues A., Hallet V. 2003, Comparison of aquifer vulnerability assessment techniques. Application to the Neblon River basin (Belgium), Environmental Geology, 44, 881-892.

12. Karaouzas I., Dimitriou E., Skoulikidis N., Gritzalis K., Colombari E. 2009, Linking Hydrogeological and Ecological Tools for an Integrated River Catchment Assessment, Environ Model Assess, 14, 677-689.

13. Karatzas G. and Psarropoulou E. 2014, Pollution of nitrates - Contaminant Transport in heterogeneous porous media: A case study of the coastal aquifer of Corinth, Greece, Global NEST Journal, 16 (1), 9-23.

14. Kazakis N. and Voudouris K. 2015, Groundwater vulnerability and pollution risk assessment of porous aquifers to nitrate: Modifying the DRASTIC method using quantitative parameters, Journal of Hydrology, 525, 13-25.

15. Kazakis N., Voudouris K., 2011, Comparison of three applied methods of groundwater vulnerability mapping: A case study from the Florina basin, Northern Greece, Advances in the Research of Aquatic Environment, Part of the series Environmental Earth Sciences, Springer, pp. 359-367.

16. Luoma S., Okkonen J., Korkka-Niemi K., 2016, Comparison of the AVI, modified SINTACS and GALDIT vulnerability methods under future climate-change scenarios for a shallow low-lying coastal aquifer in southern Finland, Hydrogeology Journal, doi:10.1007/s10040-016-1471-2.

17. Martínez-Bastida J.J., Arauzo M., Valladolid M. 2010, Intrinsic and specific vulnerability of groundwater in central Spain: the risk of nitrate pollution, Hydrogeology Journal, 18, 681-698.
18. Matiatos I. 2016, Nitrate source identification in groundwater of multiple land-use areas by combining isotopes and multivariate statistical analysis: A case study of Asopos basin (Central Greece), Science of the Total Environment, 541, 802-814.

19. Nobre R.C.M., Rotunno Filho O.C., Mansur W.J., Nobre M.M.M., Cosenza C.A.N. 2007, Groundwater vulnerability and risk mapping using GIS, modeling and a fuzzy logic tool, Journal of Contaminant Hydrology, 94, 277-292.

20. Panagopoulos G.P., Antonakos A.K., Lambrakis N.J. 2006, Optimization of the DRASTIC method for groundwater vulnerability assessment via the use of simple statistical methods and GIS, Hydrogeology Journal, 14, 894-911.

21. Polemio M., Casarano D., Limoni P. P. (2009), Karstic aquifer vulnerability assessment methods and results at a test site (Apulia, southern Italy), Nat. Hazards Earth Syst. Sci., 9, 1461-1470.

22. Psomiadis, E. (2010), Geomorphologic and Environmental Changes Research in the Sperchios' River Basin Utilizing New Technologies. PhD Thesis elaborated at the Agricultural University of Athens, Laboratory of Mineralogy-Geology.

23. Pisciotta A., Cusimano G., Favara R., 2015, Groundwater nitrate risk assessment using intrinsic vulnerability methods: A comparative study of environmental impact by intensive farming in the Mediterranean region of Sicily, Italy, Journal of Geochemical Exploration, Vol. 156, pp. 89-100.

24. Sorichetta A, Ballabio C, Masetti M, Robinson GR Jr, Sterlacchini S., 2013, A comparison of data-driven groundwater vulnerability assessment methods, Ground Water, 51 (6): 866-879.

25. Vias J.M., Andreo B., Perles M.J., Carrasco F., Vadillo I., Jimenez P. 2006, Proposed method for groundwater vulnerability mapping in carbonate (karstic) aquifers: the COP method, Hydrogeology Journal, 14, 912-925.

26. Voudouris K., 2006, Environmental Hydrogeology, AUTH, Thessaloniki, pp. 169-181.

27. Voudouris K., Kazakis N., Polemio M., Kareklas K. 2010, Assessment of Intrinsic Vulnerability using the DRASTIC model and GIS in the Kiti Aquifer, Cyprus, European Water, 30, 13-24.

28. Zhang W.L., Tian Z.X., Zhang N., Li X.Q. 1996. Nitrate pollution of groundwater in northern China. Agriculture Ecosystems \& Environment, 59, 223-231.

29. Zwahlen F. 2003, Vulnerability and Risk Mapping for the Protection of Carbonate (Karst) Aquifers, COST Action 620, Final Report. 